\title{
ALINHAMENTO ESTRATÉGICO DA TECNOLOGIA DE INFORMAÇÃO E INTELIGÊNCIA COMPETITIVA
}

\section{INFORMATION TECHNOLOGY AND COMPETITIVE INTELLIGENCE STRATEGIC ALIGNMENT}

\author{
Leonel Cezar Rodrigues ${ }^{1}$; Marcelo Jorge Fernandez ${ }^{2}$ \\ ${ }^{1}$ Universidade Nove de Julho - UNINOVE/Fundação de Apoio ao Instituto de Pesquisas \\ Tecnológicas - Fipt leonelcz@ipt.br \\ ${ }^{2}$ Centro de Ensino Superior de Blumenau - CESBLU/Cremer S/A - Produtos Têxteis e Cirúrgicos \\ marcelo@cremer.com.br
}

\begin{abstract}
Resumo
O sucesso de uma empresa hoje depende crescentemente, da estratégia de seu negócio. A estratégia de negócio, no entanto, requer eficácia operacional, que por sua vez, depende da sincronia entre a estratégia de negócio e os recursos capacitadores organizacionais: Tecnologia de Informação (TI) e Inteligência Competitiva (IC). A TI é o mecanismo agilizador da realização da estratégia. A IC alimenta as premissas do negócio. O objetivo desta pesquisa foi verificar a realização de tais premissas na percepção dos gerentes em nível médio da Cremer $S / A$, no processo de reestruturação de sua crise entre 1998 e 2001. Realizou-se para tanto, uma pesquisa paramétrica entre os gerentes desta empresa. Verificou-se o nivel de alinhamento da estratégia de TI e a estratégia corporativa, bem como o cumprimento dos processos de mudança orientados pelo sistema de IC da empresa, com base no Modelo do Processo de Sistema de Inteligência Competitiva (MOSIPIC), de Riccardi e Rodrigues (2003). Os principais resultados indicaram um excelente alinhamento da TI e consistente observância do processo e dos elementos do MOSIPIC. Como o modelo propõe, a Cremer mostrou capacidade de recuperação, baseada numa sólida estratégia corporativa de recuperação.
\end{abstract}

Palavras-chaves: Tecnologia da informação; Inteligência competitiva; Estratégia corporativa.

\section{Introdução}

A competitividade global está obrigando as organizações estarem sempre reavaliando suas estratégias de atuação. Ora direcionam-se para a busca de novos mercados, ora para fusões e aquisições, ora para o lançamento de novos produtos, ou para a formação de parcerias estratégicas, ou ainda para o estabelecimento de novos canais de distribuição. Todos estes movimentos visam a determinar a melhor forma de garantir resultados, sejam eles financeiros, ou de participação no mercado.

Uma organização que tenha o mais bem definido posicionamento estratégico sempre 
encontrará barreiras que estarão se interpondo entre sua estratégia e sua eficácia operacional. Uma estratégia, portanto, para ser implementada com sucesso, implica revisar os processos de negócios, ou introduzir novas formas de executar as operações da empresa. Esses e novos processos, por sua vez, requerem dados ou informações para que possam ser executados, acompanhados e avaliados, de forma a verificar se a estratégia planejada está funcionando e trazendo os resultados esperados. Como os processos foram modificados, é provável que a estrutura organizacional da empresa seja alterada: criadas novas áreas, fusão de áreas, uso de terceiros e outros. Para tanto, é necessário que se tenha bem definido os recursos que devem estar disponíveis para sustentar as novas estratégias, onde a tecnologia da informação ocupa lugar de extrema importância.

Prahalad e Krishnan (2002) mostram nos resultados de sua pesquisa que as organizações relatam freqüentemente que a infra-estrutura de TI não acompanha o nível de desejo de inovação. O desalinhamento da estratégia de TI é, em geral, um empecilho para a implementação de mudanças no negócio. De uma forma geral, as organizações ainda estão insatisfeitas com a qualidade e a assiduidade da geração de informações para o gerenciamento do negócio e a tomada de decisões. Isso significa que ferramentas como business intelligence, data warehouse departamental e corporativo e consulta $a d$ hoc a dados de vendas e de clientes, isto é, o sistema de inteligência competitiva (IC) é necessário para garantir que os executivos estejam preparados para aproveitar as oportunidades disponíveis para garantir maior eficácia e desempenho de suas organizações.

Porém, não se pode afirmar que ao alcançar um sincronismo entre estratégia de negócios e infra-estrutura de TI, uma organização tenha alcançado todos os requisitos exigíveis para o sucesso de seu negócio. Isto é especialmente verdadeiro, num momento de crise na organização. Em adição, o processo de mudança deve ser induzido por um sistema de IC. É provável, por outro lado, que este sincronismo dê à organização também a oportunidade de incorporar o processo de inteligência competitiva e lhe permita iniciar o processo de mudança.

Mudanças não podem acontecer de forma aleatória, sob pena de transformarem-se em conflito. Assim, é racional pensarmos que uma mudança, para ter seus efeitos desejáveis tenha que ser planejada e com metas transformacionais claramente definidas. Ademais é mais fácil, para chegar-se aos objetivos de uma mudança, que seu planejamento obedeça a um modelo, esquema, processo ou método. O sistema de IC, indutor de mudanças organizacionais aqui utilizado foi o modelo conceitual (modelo sistêmico do processo de inteligência competitiva - MOSIPIC) de Riccardi e Rodrigues (2003). O MOSIPIC parece representar adequadamente os elementos e fatores intervenientes num processo de mudança organizacional, sob a influência de um Sistema de Inteligência Competitiva.

Há condições, porém, para o funcionamento do modelo. Uma das condições exigível é de que o papel da TI no negócio esteja claramente definido para organização e definitivamente a 
serviço da estratégia corporativa. Em outras palavras, que a TI esteja alinhada à estratégia corporativa. Uma segunda condição é de que o sistema de IC da organização possa determinar o direcionamento da mudança organizacional.

A pesquisa tem como objetivo básico verificar a aderência do processo de operacionalização do sistema de IC e o nível de alinhamento da estratégia de TI com a estratégia corporativa de recuperação do Grupo da Cremer S/A.

A Cremer, uma organização do setor têxtil, situada em Blumenau-SC, atua no mercado nacional e internacional, servindo à área da saúde. Com aproximadamente 1.700 funcionários, a Cremer no ano de 2003 obteve um faturamento bruto anual de aproximadamente R\$ 180.000.000,00. Esteve preste a sofrer falência em 1997. Sua estratégica de recuperação foi apostar na infra-estrutura de TI e promover a mudança em sua cadeia de valor baseando-se em seu sistema de IC.

\section{Sistemas de informação como recurso estratégico}

O papel estratégico dos sistemas de informação envolve a utilização da tecnologia da informação para desenvolver produtos, serviços e capacidades que confiram a uma empresa vantagens estratégicas sobre as forças competitivas que ela enfrenta no mercado mundial. O’Brien (2001, p.282) destaca que, "este papel gera sistemas de informações estratégicas, os quais apóiam ou moldam a posição e estratégias competitivas de uma empresa”.

De acordo com O’Brien (2001) um sistema de informação estratégica pode ser um MIS, um DSS ou um ESS que ajude uma organização a obter uma vantagem competitiva, reduzir uma desvantagem competitiva ou alcançar outros objetivos estratégicos. Uma empresa pode sobreviver e ter sucesso em longo prazo se ela desenvolver eficazmente estratégias para enfrentar as cinco forças competitivas de Porter $(1980,1985)$.

$\mathrm{O}$ rápido crescimento da Internet, intranets, extranets e outras redes globais interconectadas nos anos 90 alterou radicalmente o potencial estratégico dos sistemas de informação nos negócios. Esta ligação em rede empresarial global revolucionou a computação nas empresas e entre as organizações, conseqüentemente alterou as comunicações e colaboração que apóiam as operações empresariais gerando um novo ambiente para os negócios, proporcionando o aumento da escala de uso dos negócios eletrônicos.

\subsection{Os sistemas de informação com o aporte da TI moderna}

A nova geração de organização é levada a investir na implantação de sistemas de informação 
que tenham implementados em seus processos as atividades da cadeia de valor, descrita por Porter (1986). Descritos anteriormente estes sistemas são identificados como Enterprise Resource Planning e o Customer Relationship Management. Proporcionando então, a base para construção de Data Warehouses, fonte para o desenvolvimento de Data Warehousing através de ferramentas de Business Intelligence (BI).

De acordo com Jamil (2001), por ferramentas de BI compreende-se técnicas, métodos e ferramentas que possibilitam ao usuário analisar dados e com base nestas análises emitir respostas que possam subsidiar objetivamente e confiavelmente os processos de decisão numa empresa. Estas ferramentas proporcionam o desenvolvimento de um ambiente necessário para um negócio competitivo inteligente dispondo da integração de SIGs, DSSs e ESSs.

A utilização de Business Intelligence através de ferramentas apropriadas pode proporcionar para as organizações a implantação de sistemas de informação que possam absorver novos conceitos na gestão das informações estratégicas, como, por exemplo, o Balanced Scorecard (BSC). De acordo com Kaplan (1997), empresas inovadoras estão adotando a filosofia do scorecard para viabilizar processos gerenciais críticos do tipo tradução a visão estratégica, medidas estratégicas, alinhamento de iniciativas estratégicas e outros.

As ferramentas de desenvolvimento de BI são instrumentos poderosos na construção de BSC, que pode ser encontrado em algumas ferramentas, como um dos módulos de desenvolvimento. Juntos, Business Intelligence e Balanced Scorecard são ferramentas poderosas para gerar informações táticas e estratégicas, assim como monitorar o desempenho das organizações através da medição de indicadores.

Entretanto, de acordo com Rodrigues (2003), BI independente dos tipos de TI aplicadas, são ações executadas a partir de decisões baseadas em informações estratégicas e táticas produzidas nas organizações direcionadas por um processo sistêmico de inteligência competitiva. Assim, não é a tecnologia da informação que garante o a inteligência do negócio, mas as estratégias corporativas com as quais a TI estiver alinhada.

\subsection{E-Business}

As organizações inovadoras estão começando a automatizar, organizar, padronizar e estabilizar os serviços oferecidos para criar e manter sustentáveis relações intermediadas por computadores em todo o ciclo de vida de um e-business. Kalakota e Robinson (2002, p.24) mencionam que "além de englobar o comercio eletrônico, o e-business inclui atividade de contato e de retaguarda que formam o mecanismo principal do negócio moderno [...]”. Não se trata apenas de transações de compra e vendas pela Internet ou outra rede eletrônica. “ [...] É uma estratégia global de redefinição 
dos antigos modelos de negócios, com o auxílio de tecnologia, para maximizar o valor do cliente e os lucros".

Em fim, de acordo com os autores, e-business é qualquer transação de negócios feita através de um canal eletrônico. No contexto de e-business, a internet é uma peça que compõe a infraestrutura que está por trás de um negócio eletrônico, um novo ambiente.

O projeto de e-business e sua arquitetura de aplicação tornaram-se temas centrais de reuniões de diretoria à medida que mais empresas integram as aplicações para agilizar as operações e entrar na competição do comércio eletrônico.

Kalakota e Robinson (2002, p.140) recomendam que "unir aplicações isoladas em uma arquitetura coesa é o processo central da execução do e-business". Projetos de negócios modernos são construídos com blocos modulares bem integrados chamados de aplicações empresariais, os quais fornecem uma plataforma padrão para as aplicações, como planejamento de recursos empresariais ou Enterprise Resorce Planning (ERP), gerenciamento do relacionamento com o cliente ou Customer Relationship Management (CRM). Tais aplicações empresariais formam a espinha dorsal da empresa moderna. Ainda segundo os autores, as aplicações de CRM é a linha de frente do e-business e as aplicações de ERP são a retaguarda. E a exigência destas grandes estruturas de aplicação proporcionou o crescimento do mercado de aluguel destas ou Aplication Service Provider (ASP), que nos últimos anos tornou-se uma alternativa para as organizações.

\section{Sincronismo da Infra-Estrutura de Ti com a Estratégia de Negócios}

As organizações estão em continua busca do sincronismo da estratégia e a tecnologia da informação porque sabem da vantagem competitiva que ganharão. Porém, é um grande desafio que poucos até o momento conseguem superar.

Para Prahalad e Krishnan (2002), empresas como Cemex, Keebler, Amazon and GE Lighting, prestaram atenção para criar novas capacidades das suas infra-estruturas de informação. Conseqüentemente, não conseguiram simplesmente alinhar a TI com a estratégia de negócios, mas fizeram a TI integrar parte da estratégia. "Isto é uma contínua e dinâmica sincronização das competências intrínseca dentro da infra-estrutura de informação e a exigência da estratégia" (PRAHALAD e KRISHNAN, 2002, p. 26).

Em sua pesquisa com mais de 500 executivos no mundo, os autores descobriram que os respondentes achavam que a infra-estrutura de TI em suas empresas está aquém de seus anseios e necessidades de mudanças. Numa escala de 0 a 5, o grau de mudanças na Industria, na Direção Estratégia, a Capacidade para mudar da empresa, qualidade da infra-esturura e a capacidade 
colaborativa dentro da organização foram avaliados em média em 2,5. Pode-se observar pela diferença para o ideal (5), uma grande distância entre a realidade e o que desejariam os gerentes. Para que a distância seja diminuída, Prahalad e Krishnan (2002, p.29), sugerem que para "entender a capacidade, impedimentos e riscos em sua infra-estrutura de informação, os gerentes de negócios e os gerentes de TI necessitam de uma estrutura de trabalho comum". As organizações que ainda não incorporaram este processo de sincronismo na sua cultura é preciso dispor de alguns instrumentos, para iniciar este processo de forma planejada. Os parâmetros da pesquisa de Prahalad e Krishnan (2002) serviram de base para a pesquisa de alinhamento da TI com a estratégia corporativa na Cremer, nosso campo de pesquisa.

\section{Inteligência Competitiva}

O conceito de inteligência competitiva - monitoramento de informações externas do ambiente operacional da empresa com vistas à formulação de estratégias competitivas eficazes tem cerca de duas décadas apenas na administração das empresas. As considerações sobre monitoramento do ambiente externo, no entanto, começaram muito antes. Desde a década de 60, com a introdução do planejamento estratégico e posteriormente com Porter $(1980,1985)$ que chama a atenção para a necessidade das empresas criarem vantagens competitivas. Porter (1986) insiste que a análise competitiva é importante não apenas para a formulação das estratégias empresariais, mas também em finanças, marketing, produção e logística.

A formulação das estratégias empresariais, no entanto, deve estar fundamentada nas cinco formas de definições de estratégia: plano, estratagema, modelo/padrão, posição e perspectiva (MINTZBERG, 1987; MINTZBERG e QUIN, 2001). Segundo estes autores, a noção de estratégia é a integração destas cinco definições. Como plano, traça um guia de ação futura; como estratagema, um guia para realizar competição, destinado a abalar os concorrentes, sendo mais ameaça do que ação propriamente dita; como modelo/padrão focaliza as ações emergentes que afloram pela organização permitindo manter a coerência ao longo do tempo; como posição, incorpora o ambiente externo, especificamente escolhe uma localização no ambiente, definindo um nicho e ali se aloja; e como perspectiva traz para a análise o ambiente interno, olhando para dentro e para o alto, em direção a uma visão mais ampla.

Em essência, se os conceitos estratégicos são para desempenhar um papel efetivo em determinar o crescimento e a sobrevivência de uma empresa, então esses conceitos devem ser realinhados, usando uma abordagem que enfatize os fundamentos básicos da natureza combativa das condições atuais do ambiente empresarial. Dada a natureza competitiva do mercado e as 
limitações, uma postura de ataque e defesa requer uma estratégia de negócio semelhante a estratégia militar. Nesta situação, uma ferramenta estratégica de análise se faz naturalmente imprescindível, a Inteligência Competitiva.

Segundo Lesca (1996), a inteligência competitiva ou a vigília estratégica é o processo informacional através do qual a organização realiza a escuta "antecipativa" dos "sinais fracos" do seu ambiente sócio-econômico com o objetivo criativo de descobrir oportunidades e de reduzir os riscos ligados à incerteza. A importância do processo encontra-se em montar o quebra-cabeça de informações em buscas de utilização estratégica para as organizações.

Para Kahaner (1997), a inteligência competitiva é um programa sistemático que visa a busca e análise das informações sobre os seus concorrentes ativos e tendências de negócios em geral para o futuro de uma empresa. Teixeira Filho (2003) define inteligência competitiva como o acompanhamento sistemático do ambiente de negócio monitorando as informações sobre clientes, fornecedores, concorrentes, agentes reguladores, governo, novas tecnologias e tudo mais que possa influir no mercado da empresa. Por fim, Riccardi e Rodrigues (2003, p.186) oferecem uma importante contribuição para o entendimento da inteligência competitiva: "se entende por tal, a um sistema pragmático de recoleção, análise e distribuição das atividades dos competidores e das tendências dos negócios para poder assegurar consistência aos objetivos da empresa”.

\subsection{Inteligência Competitiva nas Empresas}

As empresas estão, agora, diante da necessidade de selecionar estratégias para deter um ataque contra seus produtos ou serviços e, por outro lado, selecionar estratégias para atacar seus competidores. Para Suave (2003), a inteligência competitiva é utilizada pelas empresas, num processo coletivo e voluntário, pelo qual procuram ativar e assimilar as informações, antecipando-se a mudanças relativas a seu ambiente sócio-econômico. É um verdadeiro processo de "vigília", realizado dentro do objetivo de criar as oportunidades de negócios e reduzir os riscos ligados às incertezas.

É importante observarmos que o objetivo da inteligência competitiva não é procurar tendências, mas sim levar à capacidade de "prever" o que será a ser uma tendência num futuro próximo. Assim, quando um comportamento ou fenômeno qualquer começar a ser observado como tendência, a empresa que tiver inteligência competitiva já terá - antecipadamente - o conhecimento da informação. Terá, portanto, se preparado para as adaptações necessárias à sua adaptação aos novos padrões, requeridos pela nova tendência.

Mas é importante salientar que, Riccardi e Rodrigues (2003) chamam a atenção de que 
quando se fala de inteligência competitiva convém deixar claro a diferença entre Informação e Inteligência. A Informação é realidade e a Inteligência não é uma função, e sim um processo que recoleta pedaços de informações que são filtrados, reagrupados e analisados e que constituem aquilo que necessitam os gerentes para tomar decisões.

Em fim, na luta pela competitividade as empresas precisão implantar um processo de inteligência competitiva, e para isto necessitam adotar uma metodologia. Riccardi e Rodrigues (2003) propõem um modelo sistêmico do processo de inteligência competitiva, o MOSIPIC.

\subsection{O modelo MOSIPIC}

O modelo sistêmico do processo de inteligência competitiva (MOSIPIC) foi proposto por Riccardi e Rodrigues (2003), com o objetivo de satisfazer a intenção de uma empresa inteligente e competitiva de alcançar os resultados para atuar no mundo dos negócios.

Figura 1 Modelo Sistêmico do Processo de Inteligência Competitiva OSIPIC

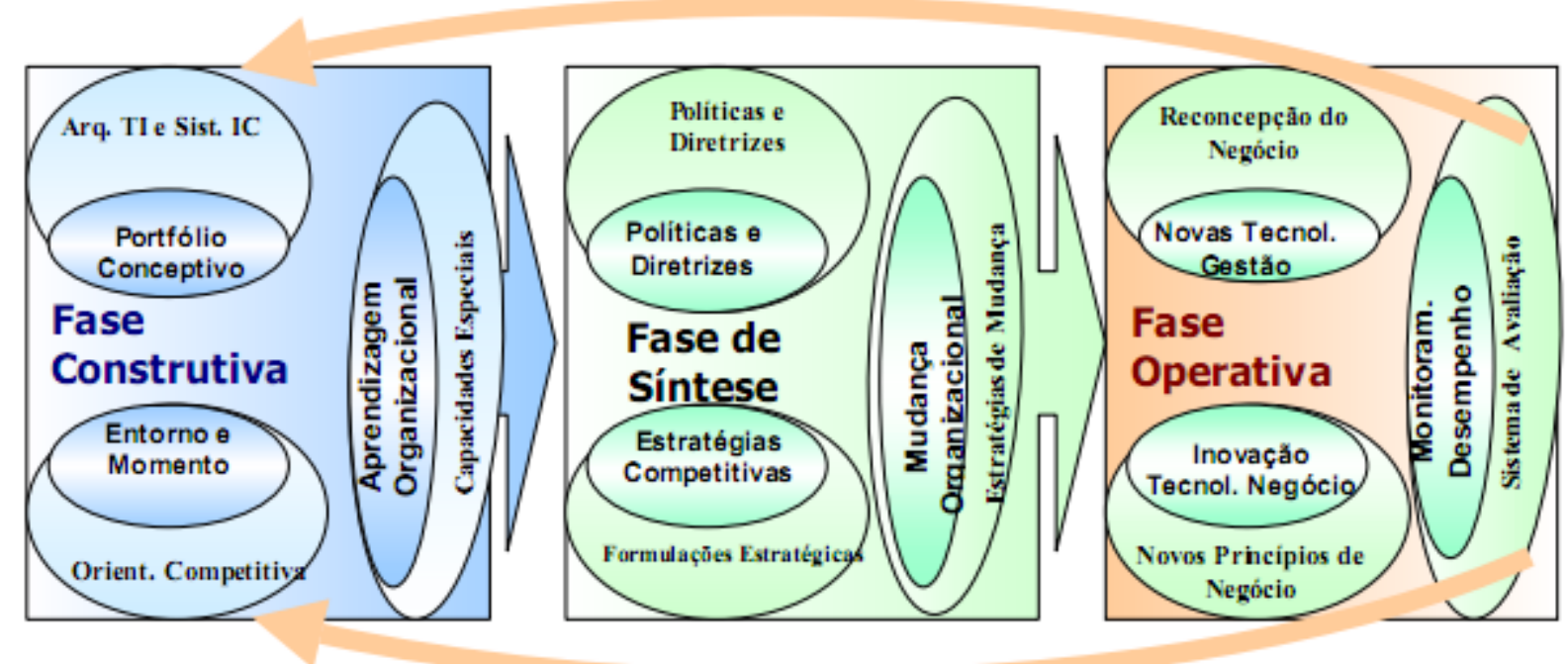

Fonte: Adaptado de RICCARDI, R. e RODRIGUES. L.C. Inteligência Competitiva en los Negócio y en lãs Organizaciones. Buenos Aires (AR): Macchi, 2003, p. 242.

Como mostra a figura 1, o MOSIPIC está constituído por três etapas distintas: (a) construtiva; (b) a de Síntese; e (c) a Operativa. Cada etapa constitui-se de três fases características. A etapa Construtiva envolve o portfólio conceptivo, o entorno e momento e a aprendizagem organizacional. A etapa de Síntese envolve as seleções de políticas e diretrizes, as estratégias competitivas e a mudança organizacional. Por fim, a etapa Operativa é constituída pelas fases da geração de novas tecnologias de gestão, de inovação na tecnologia de negócio e de monitoramento 
do desempenho.

Na etapa Construtiva a empresa preocupa-se com a criação das condições competitivas que a devem ser alcançadas. A fase do Portfólio Conceptivo se preocupa em criar condições que permitam a empresa alcançar uma alta competitividade sustentada e sustentável. É alimentada pela arquitetura de TI e sistema de IC que forma o capital intelectual da empresa por meio dos sistemas de informações. Nesta etapa, a fase do Entorno e Momento diz respeito à orientação competitiva da organização. Nesta fase, procura-se em determinar os elementos ambientais que influenciam o posicionamento competitivo, por meio da identificação da tendência forças contributivas e das forças impeditivas ao negócio, existentes no seu entorno. E a fase da Organização em Aprendizagem se ocupa de por à disposição dos gerentes, o veículo intelectual que deve introduzir na organização a nova mentalidade requerida para aquisição de conhecimento, e sistematização da aprendizagem organizacional.

A etapa de Síntese centra seus esforços em assegurar ao negócio ou à organização, uma capacidade de tomar decisões em situações críticas. Na primeira fase desta esta etapa, a Seleção de Políticas e Diretrizes acontecem às políticas e diretrizes internas e externas que determinam os parâmetros que orientam os pensamentos, as decisões e ações na empresa.

A segunda fase desta etapa é a de Estratégias competitivas, que diz respeito às estratégias formuladas com base nas informações geradas pelo sistema de Inteligência Competitiva. Compõem-se de duas dimensões. Uma refere-se às geração da motivação organizacional (pensamento estratégico e intento estratégico). E a outra ao desenvolvimento das capacitações na organização, necessárias para competir com êxito (capacidades especiais e recurso e competências essenciais). Por fim, a terceira fase, Mudança Organizacional refere-se ao produto natural das estratégias elegidas na fase anterior. É um processo que pode ocorrer através na forma de mudança incremental; mudança evolutiva; mudança revolucionaria e mudança transformadora.

A etapa Operativa preocupa-se essencialmente com a necessidade, exigida pelo processo de mudança, de introduzir na empresa novas tecnologias de gestão que devem sustentar a reconcepção do negócio.

Novas tecnologias de gestão ajudam na Inovação da Tecnologia de Negócio, a segunda fase desta etapa. A inovação na tecnologia de negócio supõe novos princípios organizacionais e de negócios que empurram a organização para novas dimensões e lhe dão novo ímpeto competitivo.

A terceira fase desta etapa é o monitoramento de desempenho. Esta fase baseia-se no processo de avaliação da diretriz de mudança adotada pela organização. Este processo de avaliação implica em três componentes estratégicos: participação, aprendizado e avaliação. 


\section{Método de pesquisa}

A pesquisa, de natureza estatístico-descritiva, amostrou todos os representantes do comitê executivo e os coordenadores de processos do Grupo Cremer S/A, composta por três unidades de negócio e oito Centros de Distribuição. Uma das três unidades de negócio é representada pela unidade de injeção de plásticos de médio porte, a Plásticos Cremer, com 5 respondentes. As outras duas unidades são representadas pela matriz e filial da CREMER S.A., com 19 respondentes na matriz e 7 na filial, a fábrica de adesivos industriais e hospitalares. Cada centro de distribuição teve a participação de 1 respondente. O comitê executivo teve a participação de 6 executivos. A amostra, portanto, somou um total de 45 respondentes.

Tanto o sincronismo da TI, quanto o nível de aderência dos processos de mudança, direcionados pelos sistemas de IC da Cremer ao MOSIPIC foram identificados pela quantificação das percepções dos respondentes, segundo uma escala Likert, com variações entre 0 (discordo totalmente) e 5 (concordo totalmente).

\section{Análise e Interpretação dos Resultados}

Como proposto nos objetivos, esta pesquisa visa a verificar, em essência, se de fato, houve aderência no processo de reestruturação da Cremer, ao MOSIPIC de Riccardi e Rodrigues (2003). A relevância dessa aderência advém de duas evidências preliminares. Uma de que a reestruturação da Cremer foi fundamentalmente assentada sobre sua capacitação em TI. A empresa reconcebeu seu negócio sobre as promessas da TI de agilização, conveniência, produtividade, abaixamento de custo e conectividade interorganizacional.

\subsection{Sincronismo da TI com a Estratégia corporativa}

Os resultados da pesquisa sobre o nível de sincronismo entre as estratégias corporativas e as de TI, observou-se um elevado grau de sincronismo entre ambas, nesta empresa. Todas as questões atingiram acima de $82 \%$ de sincronia entre o real e o esperado. Das onze questões, quatro foram além do esperado: os subitens "b" e "c" da questão de número 6, o subitem "b" da questão de número 11 e as questões de números 7 e 9 atingiram mais de $100 \%$ do esperado. No geral, o grau de sincronismo foi de $95 \%$ entre o real e o esperado. O sincronismo descrito acima pode ser melhor observado no gráfico 1: 


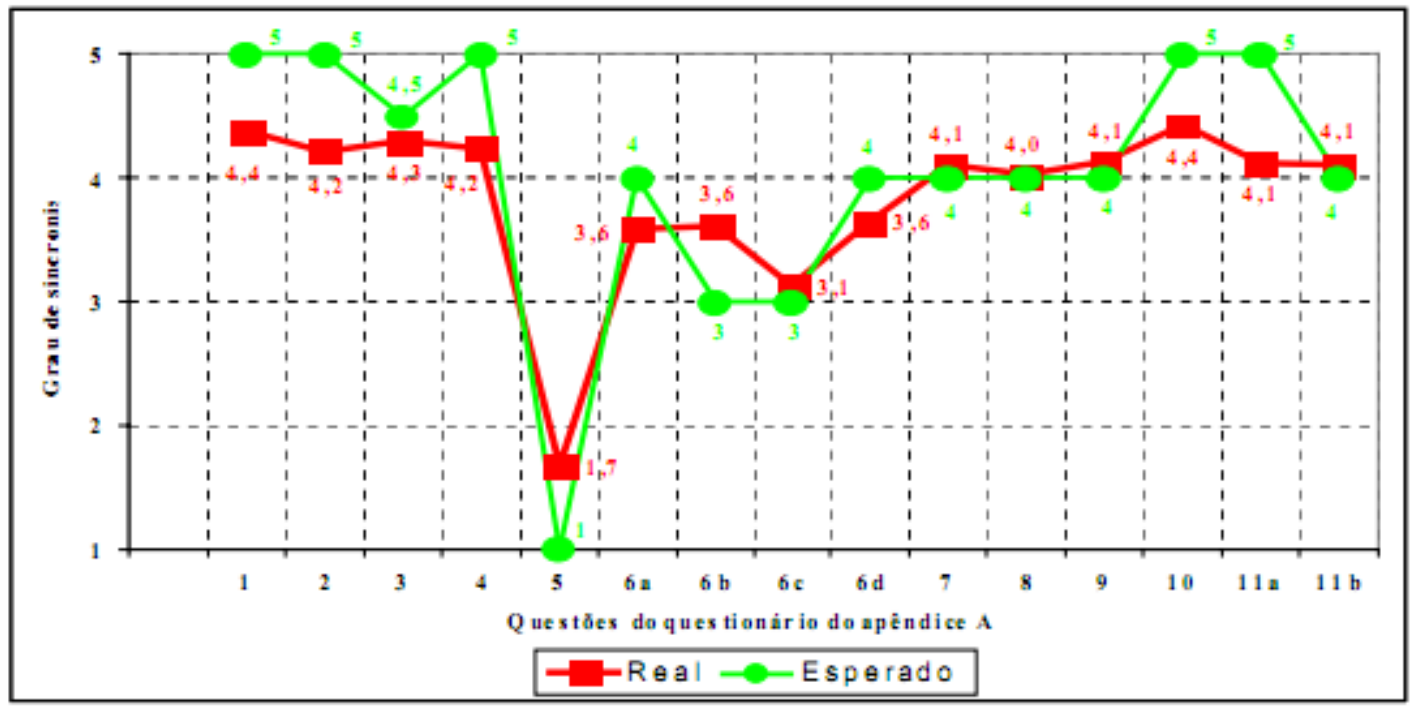

Fonte: dados de pesquisa

Observando o gráfico, no eixo $\mathrm{X}$ estão as questões do questionário e no eixo $\mathrm{Y}$ estão os graus de sincronismo. A linha verde representa o grau esperado para cada questão e linha vermelha o grau real de sincronismo. Verifica-se que somente o item da questão 6 apresentou diferença acentuada do esperado em relação ao real e que em alguns itens o real foi além do esperado. Um perfil bastante diferente dos perfis de sincronismo dispersos obtidos nas pesquisas de Prahalad e Krishnan (2002).

O sincronismo da estratégia corporativa da Cremer e sua estratégia de TI podem sugerir que o processo de mudança na organização esteja também obedecendo a parâmetros de eficácia operacional de processos, descritos em Hutt e Speh (2002). O MOSIPIC sugere que a mudança na organização, direcionada pelo sistema de Inteligência Competitiva, deva observar determinados parâmetros, de forma sistêmica, isto é, que a mudança deva conter os parâmetros e realizá-los de forma seqüencial para que a mudança se consolide e tenha os melhores resultados para a organização.

A Cremer, como mostram os resultados da pesquisa do sincronismo dinâmico entre estratégia corporativa e de TI, apresenta elevado grau de sincronismo. Como o sincronismo é característica típica da efetividade da estratégia vigente na organização, os outros elementos constituintes desta estratégia, determinantes das mudanças organizacionais, especificamente aqueles contidos nos sistemas de IC, estão supostamente apropriados. Pressupõe-se, desta forma, que a Cremer observa os requisitos do processo de mudança organizacional, segundo o MOSIPIC. 


\subsection{Aderência da mudança ao processo sistêmico de IC}

Por razões de espaço, simplificamos a mostra e discussão dos resultados de aderência, fixando- nos apenas no Gráfico 2, que mostra um resumo da percepção dos respondentes acerca do grau de aderência da mudança prevista na reestrutura da empresa, aos processos previstos no MOSIPIC.

Cada etapa e cada fase foram escrutinadas junto aos respondentes, para obter suas percepções da presença e observância dos elementos de cada fase que compõem as três etapas. Os resultados mostram que $41,6 \%$ dos respondentes demonstraram que a Cremer parece ter observado amplamente os requisitos do processo de mudança contidos no modelo MOSIPIC de Riccardi e Rodrigues (2003). 40,4\% demonstraram que os requisitos são observados quase que na totalidade. A grosso modo, portanto, cerca de $82 \%$ dos respondentes concordam que a empresa tenha observado os elementos do MOSIPIC na sua reestruturação. Um percentual pouco significativo de 18\% representa a discordância e ausência de opinião. De modo geral, o gráfico 2 representa a constatação de que os elementos contidos no MOSIPIC são reconhecidos pela organização no seu processo de reestruturação, com base nos sistemas de inteligência competitiva.

Gráfico 2 - Aderência do grupo Cremer ao MOSIPIC

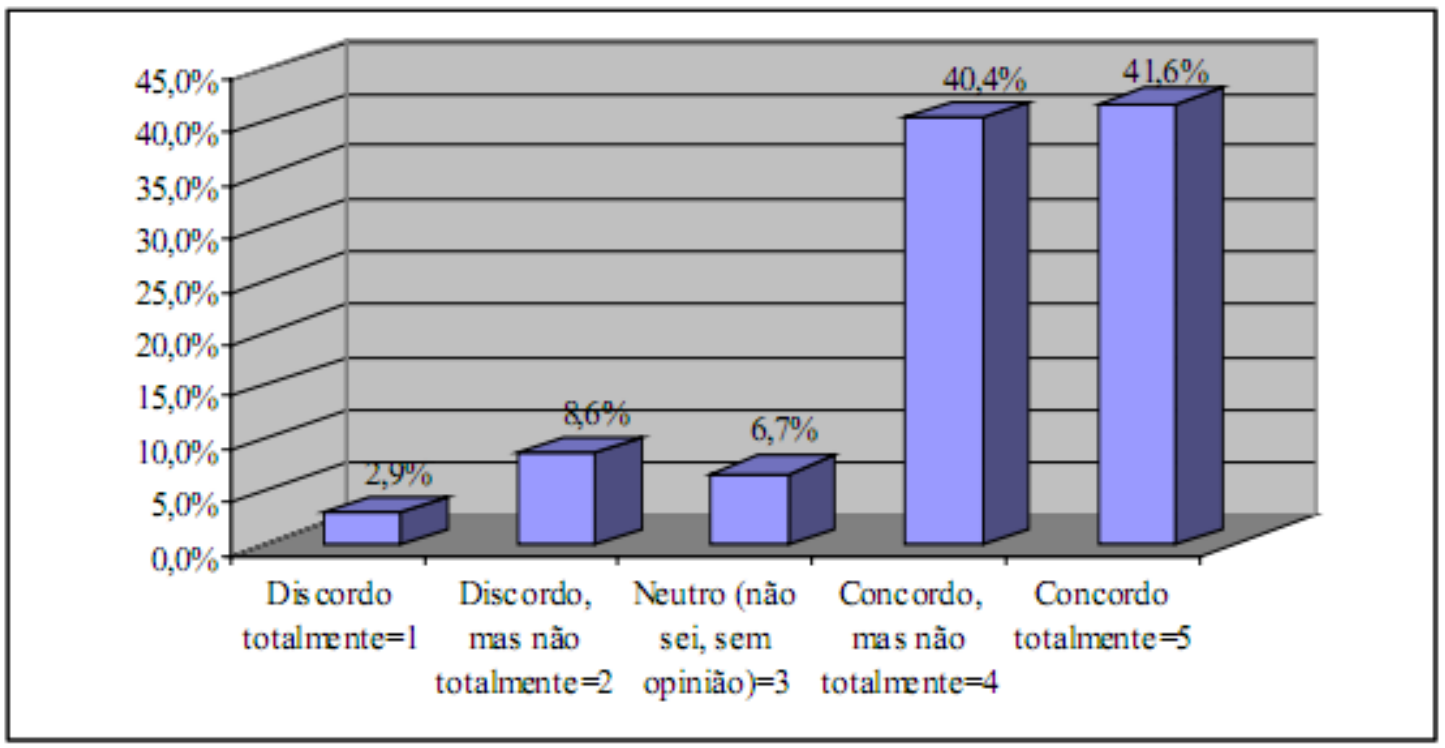

Fonte: dados da pesquisa

O gráfico 2 foi gerado com base nos dados da Tabela 1 que representa os percentuais médios de aderência em cada fase do MOSIPIC. O percentual médio de cada fase foi gerado com base nas questões do instrumento de coleta da pesquisa, que representa os elementos do MOSIPIC. 
Tabela 1 - Aderência aos processos de mudança do MOSIPIC

\begin{tabular}{|c|c|c|c|c|c|c|}
\hline ETAPA & FASES & $\begin{array}{c}1 \\
\text { (Discordo) }\end{array}$ & $\begin{array}{l}2 \text { (Discordo, } \\
\text { mas não } \\
\text { totalmente) }\end{array}$ & 3 (Neutro) & $\begin{array}{l}4 \text { (Concordo, } \\
\text { mas não } \\
\text { totalmente) }\end{array}$ & $\begin{array}{c}5 \\
\text { (Discordo) }\end{array}$ \\
\hline Etapa I & Fase I-1 & $2,6 \%$ & $8,5 \%$ & $9,3 \%$ & $41,1 \%$ & $38,5 \%$ \\
\hline Etapa I & Fase I-2 & $1,9 \%$ & $11,5 \%$ & $3,7 \%$ & $42,6 \%$ & $40,4 \%$ \\
\hline Etapa I & Fase I-3 & $0,3 \%$ & $6,3 \%$ & $7,6 \%$ & $39,4 \%$ & $46,3 \%$ \\
\hline Etapa II & Fase II-1 & $0,0 \%$ & $7,8 \%$ & $4,4 \%$ & $44,4 \%$ & $43,3 \%$ \\
\hline Etapa II & Fase II-2 & $0,0 \%$ & $9,4 \%$ & $2,8 \%$ & $33,3 \%$ & $54,4 \%$ \\
\hline Etapa II & Fase II-3 & $4,2 \%$ & $10,9 \%$ & $4,4 \%$ & $38,2 \%$ & $42,2 \%$ \\
\hline Etapa III & Fase III-1 & $4,3 \%$ & $5,9 \%$ & $5,9 \%$ & $42,8 \%$ & $41,1 \%$ \\
\hline Etapa III & Fase III-2 & $1,5 \%$ & $11,1 \%$ & $15,6 \%$ & $34,1 \%$ & $37,8 \%$ \\
\hline GERAL & & $2,9 \%$ & $8,6 \%$ & $6,7 \%$ & $40,4 \%$ & $41,6 \%$ \\
\hline
\end{tabular}

Fonte: dados da pesquisa

É importante ainda notar-se que na etapa III, as fases de novas tecnologias de gestão e inovação na tecnologia de negócio foram avaliadas de forma embutida, para facilitar a compreensão das perguntas e respostas dos sujeitos sociais da pesquisa. A fase de monitoramento de desempenho foi apontada na etapa três como a fase III-2, na Tabela 1 .

\section{Considerações finais}

A aderência aos processos de mudança organizacional indutores da realização dos objetivos e estratégias da organização propostos no MOSIPIC é relevante por várias razões. Em primeiro lugar, o MOSIPIC, como modelo de teórico, necessita sofrer os confrontos normais de sustentação racional e operacional para ser aceito como um modelo de bases científicas consistentes. $\mathrm{O}$ uso da aderência às premissa do modelo, portanto, é uma contribuição importante para o suporte à funcionalidade estratégica da TI. Em segundo lugar, o MOSIPIC abre espaço para a discussão de métodos e ferramentas gerenciais de gestão da informação e da inteligência competitiva, úteis para a gestão estratégica de organizações de qualquer natureza. Em terceiro lugar, o MOSIPIC embute igualmente a oportunidade de aprimoramento conceitual do modelo, porque traz incorporadas, contribuições de caráter pragmático.

As principais conclusões desta pesquisa podem ser resumidas nas seguintes observações. A empresa pesquisada apresenta amplo sincronismo entre a TI e as estratégias corporativas. Uma das premissas desta pesquisa era de que o sincronismo é condição necessária para que o sistema de IC possa desempenhar seu papel no suporte à realização da estratégia corporativa. 
Com relação ao nível de aderência do processo de concepção e operacionalização dos sistemas de IC do grupo Cremer ao MOSIPIC, as respostas indicaram índices significativamente elevados de aderência. Conclui-se, portanto, que de modo geral, os pesquisados identificaram os elementos tanto das etapas, quanto das fases do MOSIPIC, no processo de reestruturação da Cremer. Não apenas as etapas, mas também cada fase do modelo apresentou seus elementos com índices de aderência elevados. Porém, alguns elementos de determinadas fases do modelo.

Por fim, é importante notar-se que a aderência do processo de recuperação da Cremer, com base na TI, suporta a racionalidade do modelo, não apenas para situações de normalidade, mas também para situações anormais, em que os eventos e fatores conjunturais não são totalmente previsíveis.

\begin{abstract}
A today's corporation performance depends on her business strategy. Business strategy, however, requires operational effectiveness, which in turn, depends on the synchronism between business strategy and the organizational resources incorporated by the Information Technology and the Competitive Intelligence. IT role is a corporate strategy supporting mechanism. CI on the other hand, feeds corporate specific needs to accomplish her business objectives. Here we search to find if business objectives were accomplished through the alignment of IT and CI in their role to support organizational strategy, viewed by middle management at Cremer S/A, during her resilience after 1998-2001 crisis. We survey all middle managers at Cremer to find the level of alignment between IT and CI, based on the Model of the Competitive Intelligence System Process (Riccardi and Rodrigues, 2003). Main results indicated there was an excellent level of alignment between IT and $\mathrm{CI}$ and a consistent obedience of the process and elements of MOSIPIC. As the model indicates, Cremer showed resilience based on a solid restructuring corporate strategy.
\end{abstract}

Key-words: Information Technology; Competitive Intelligence; Corporate Strategy.

\title{
Referências
}

HUTT, M. D.; SPEH, T. W. B2B: Gestão de Marketing em Mercados Industriais e Organizacionais. $7^{\text {a }}$ Ed. Porto Alegre: Bookman, 2002.

JAMIL, G. L. Repensando a TI na Empresa Moderna. Rio de Janeiro: Axcel Books, 2001.

KAHANER, L. Competitive intelligence: how to gather, analyze, and use information to move your business to the top. New York: Touchstone, 1997.

KALAKOTA, R.; ROBINSON, M. E-business: estratégias para alcançar o sucesso do mundo digital. $2^{\text {a }}$ Ed. Porto Alegre: Bookman, 2002.

KAPLAN, R. S. A estratégia em ação: Balanced Scorecard. Rio de Janeiro: Campus, 1997.

LESCA, H.; FREITAS, H.; CUNHA, M. Instrumentalizando a Decisão Gerencial. Revista Decidir, ano 3, n. 25, p. 614, ago. 1996.

MINTZBERG, H. Crafting Strategy. Harvard Business Review, p.66-75, jul./ago., 1987.

MINTZBERG, H.; QUINN, J. B. O processo da estratégia. 4a Ed. Porto Alegre: Bookman, 2001.

O’BRIEN, J. A. Sistemas de Informação e as decisões gerenciais na era da Internet. São Paulo: Saraiva, 2001. 
PORTER, M. E. Competitive strategy. New York: Free Press/Macmillan, 1980.

Competitive advantage. New York: Free Press/Macmillan, 1985. Campus, 1986.

Estratégia Competitiva: Técnicas para Análise de Indústrias e da Concorrência. $7^{\mathrm{a}}$ Ed. Rio de Janeiro,

PRAHALAD, C. K.; KRISHNAN M. S. The Dynamic Synchronization of Strategy and Information Technology. MIT

Sloan Management Review, v. 43, n. 4, p. 24-33, 2002.

RICCARDI, R.; RODRIGUES, L. C. Inteligência Competitiva: en los negocios y en las organizaciones. Córdoba: Ediciones Macchi, 2003.

RODRIGUES, L. C. Business intelligence: the management information system next step. Book Review, v. 7, n. 3, p. 423-431, 2003. Disponível em: <http://www.blackwell-synergy.com>. Acesso em: 04 agosto de 2005.

SUAVE, I. Inteligência competitiva: a arte de enxergar primeiro. Disponível em: $<$ http://www.sites.netsite.com.br/recall/edicao26/artigo.htm>. Acesso em 06 agosto de 2005.

TEIXEIRA FILHO, J. Gestão do conhecimento, capital intelectual e inteligência competitiva.. Disponível em: $<$ http://www.bte.com.br>. Acesso em: 05 agosto de 2005.

\section{Dados completos do autor}

Nome completo: Leonel Cezar Rodrigues

Filiação institucional: Centro Universitário Nove de Julho, Centro de Pós Graduação, Programa de Pós Graduação Em Administração.

Endereço completo para correspondência (bairro, cidade, estado, país e CEP): Av. Francisco Matarazzo, 612 - Pós-Graduação - Stricto Sensu - UNINOVE Água Branca

CEP: 05001100 - SAO PAULO, SP - Brasil

Telefones para contato: (11) 36659306

e-mail: leonelcezar@terra.com.br

Recebido para publicação em: 05/12/2005

Aceito para publicação em: 17/02/2006 